\title{
OBSERVATORIO
}

\section{POETAS EN TIEMPOS DE MISERIA: LÍMITES Y RETOS DE LOS SERVICIOS DOCUMENTALES DE MUSEOS}

Javier Docampo

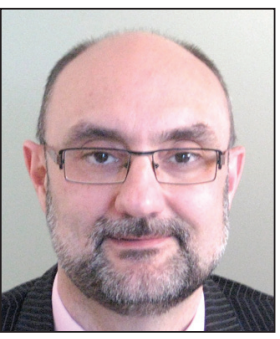

Resumen

Javier Docampo es jefe del Área de Biblioteca, Archivo y Documentación del Museo Nacional del Prado desde 2008. Anteriormente trabajó en la Universidad de Santiago de Compostela, en la Biblioteca Nacional (Sección de Dibujos y Estampas) y en la Consejería de Cultura de Castilla-La Mancha. Es licenciado en historia del arte y actualmente es miembro del Comité Permanente de la Sección de Bibliotecas de Arte de IFLA. Ha escrito y conferenciado extensamente sobre bibliotecas de arte y museos, así como sobre artes del libro (miniatura, grabado y encuadernación).

Museo Nacional del Prado, Casón del Buen Retiro Alfonso XII, 28. 28014 Madrid, España javier.docampo@museodelprado.es

La documentación en los museos debe ampliar su radio de acción a través del concepto de servicios documentales: bibliotecas, archivos y servicios de documentación tienen que trabajar conjuntamente para lograr un mejor conocimiento y difusión de las colecciones de cada museo. Si las bibliotecas muestran un futuro incierto, los archivos pueden jugar un papel relevante en el futuro de la institución. Los servicios documentales deben además abrirse desde el servicio interno a la difusión de todas sus colecciones bibliográficas, documentales y artísticas a través de los últimos desarrollos, como los propuestos por la web semántica.

\section{Palabras clave}

Documentación, Bibliotecas, Archivos, Museos, Web semántica, Tendencias, Futuro, Evolución.

Title: Poets in times of misery: limits and challenges of museum documentary services

\begin{abstract}
In museums, the scope of documentation must be extended through the concept of documentary services: libraries, archives and services of documentation have to work together to achieve a better knowledge and diffusion of the collections of each museum. If libraries have an uncertain future, archives can play an important role in the future of the institution. Documentary services must be open to everything from internal service to the diffusion of all bibliographic, documentary and artistic collections using the most recent means available, such as those proposed for the semantic web.
\end{abstract}

\section{Keywords}

Documentation, Libraries, Archives, Museums, Semantic web, Trends, Future, Evolution.

Docampo, Javier (2013). "Poetas en tiempos de miseria: límites y retos de los servicios documentales de museos". EI profesional de la información, mayo-junio, v. 22, n. 3, pp. 197-202.

\section{El difícil futuro de las bibliotecas de museos...}

A la entrada del patio trasero del Museo Reina Sofía, vía lógica para acceder a su muy concurrida biblioteca, el lector se encuentra con lo que parece desde lejos un poste de señalización y que es, en realidad, una obra de arte conceptual. En ella puede leer de forma entrecortada una frase en francés: "Pourquoi donc des poètes en temps de misère?" (figura 1). La famosa sentencia de Hölderlin, retomada por Heidegger, sirve así de inteligente (e involuntaria, nos tememos...) llamada a la reflexión a todos los que se aventuren en una de las mejores bibliotecas de museos de nuestro país: cuando llega la desgracia, cuando aprieta la crisis: ¿para qué sirven los poetas? ¿para qué sirve la cultura? o, para centrarnos, ¿para qué sirven las bibliotecas (de museos)?

Hasta hace muy poco tiempo la respuesta estaba clara, al menos en nuestro país: para atender las necesidades informativas del personal técnico del museo (conservadores, restauradores, personal de educación...) más algún investigador despistado que osaba penetrar en tan cerrados recintos. Era en general el modelo seguido por las bibliotecas de museos europeos, incluso hasta el presente, como en el 


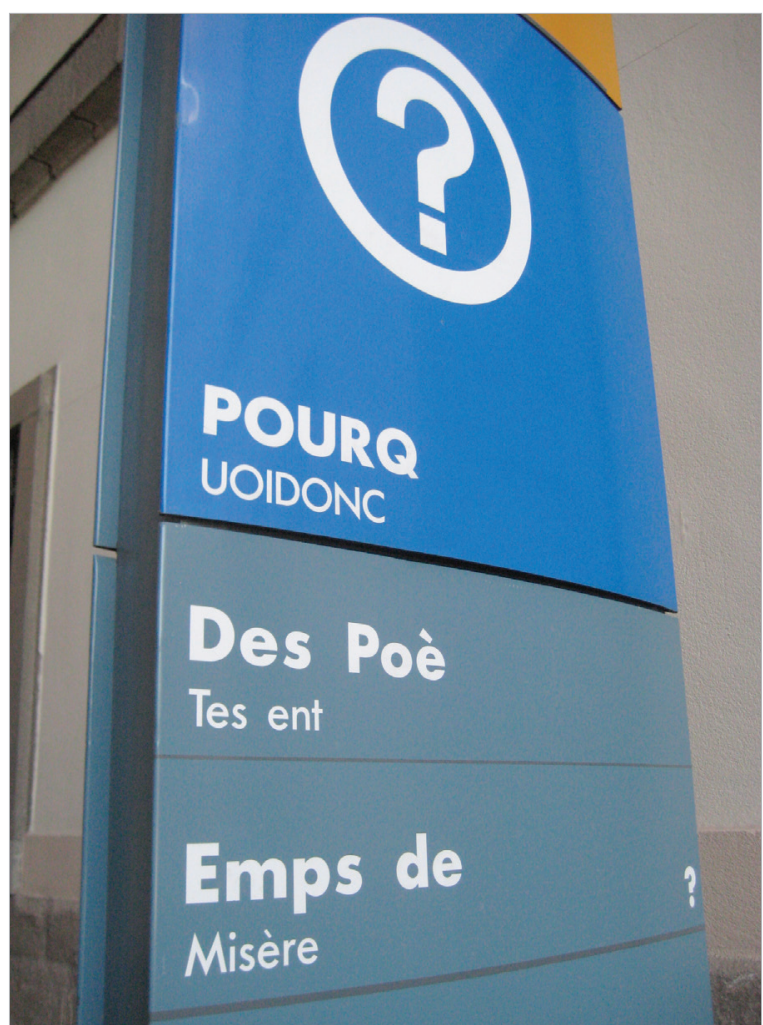

Figura 1. Museo Nacional Centro de Arte Reina Sofía http://www.museoreinasofia.es

caso de la National Gallery de Londres, que ni tan siquiera tiene un opac en la web. Enfrente se alzaba el modelo estadounidense, como fruto de las dos grandes tradiciones museológicas desarrolladas a ambos lados del Atlántico (Gómez-Martínez, 2006). En Europa los grandes museos han tenido predominantemente un origen público, sus colecciones han estado condicionadas ante todo por factores locales y de proximidad y sus objetivos han estado, al menos en un principio, orientados ante todo a la conservación del patrimonio de sus respectivos países. Por el contrario en Estados Unidos los museos nacieron y se desarrollaron como instituciones privadas, sus colecciones suelen aspirar a tener un carácter universal y ambos factores han conducido a que sus objetivos sean ante todo educativos (Benedetti, 2007).

Aunque estos dos modelos de museos se han ido acercando progresivamente y los museos europeos han ido valorando el potencial educativo de sus colecciones, las bibliotecas han seguido también caminos divergentes en los museos americanos y en los europeos (Docampo, 2010). Desde que se fundaron los primeros museos estadounidenses, las bibliotecas fueron consideradas como piezas fundamentales para el cumplimiento de sus funciones y, por ello, en la actualidad han logrado ser las más destacadas del mundo, tanto por la riqueza de sus colecciones bibliográficas, como por su apertura hacia todo tipo de públicos y por el inteligente aprovechamiento de las posibilidades ofrecidas por los desarrollos tecnológicos. Sin embargo, en Europa el camino por recorrer es aún largo, ya que, volcadas en el servicio interno como señalábamos, han tenido una escasa relevancia, de la que se escapan sólo algunos centros.
O a lo mejor este camino no es tan largo. Y no porque el desarrollo de las bibliotecas de museos vaya a ser imparable en los próximos años, sino porque probablemente éstas hayan llegado demasiado tarde. Por más vueltas que se le quiera dar, el futuro de las bibliotecas está indisolublemente ligado al de los soportes físicos que albergan, barridos progresivamente por el avance imparable de internet. Y a medida que éstos vayan desapareciendo o quedando relegados a meras curiosidades permanentemente resucitadas (como los vinilos) las bibliotecas como tales irán languideciendo. Es probable que el proceso no sea rápido, dados los obstáculos de todo tipo que ha de superar el cambio de paradigma, pero se puede pensar en no que van a durar mucho más de una generación.

El problema es qué hacer mientras tanto con las bibliotecas de museos. Una posible vía pasa por entender que las bibliotecas especializadas (y las de museos no son otra cosa) pueden ser útiles fuera de la comunidad de investigadores, ya que a medida que ha crecido el nivel educativo en los países desarrollados, también han aumentado las necesidades informativas de una población que no siempre encuentra lo que busca en las bibliotecas públicas y que no tiene acceso fácil a las bibliotecas universitarias o especializadas. Si los museos están abiertos a todos, con independencia de su nivel formativo, sus bibliotecas, concebidas como un servicio más de la institución, también deben estarlo.

Además de la apertura a nuevos públicos, otro recurso que puede alargar la existencia de las bibliotecas de museos son las redes nacionales e internacionales. Se pueden citar dos casos, Bimus a nivel nacional, que agrupa a las bibliotecas de diecinueve centros dependientes del Ministerio de Educación, Cultura y Deporte (Alonso, 2012), y Artlibraries.net a nivel internacional, con la participación de más de 100 bibliotecas de 14 países, sin que España se encuentre representada (Höyer, 2012). Sin embargo estas redes se han limitado al establecimiento de catálogos colectivos o de metabuscadores cuyo papel, después de quince años de funcionamiento de Google, es bastante residual, o a la realización de jornadas o congresos periódicos.

Si los museos están abiertos a todos, con independencia de su nivel formativo, sus bibliotecas, concebidas como un servicio más de la institución, también deben estarlo

Paradójicamente los fondos patrimoniales de bibliotecas y archivos están teniendo un papel cada vez mayor en la vida de los museos de arte contemporáneo. Desde el rol fundamental que manifiestos y revistas ejercieron en el arranque de las vanguardias históricas hasta la importancia que el concepto de archivo ha tenido en las artes plásticas desde los movimientos conceptuales, son numerosas las razones que han llenado de vitrinas y papeles las salas del Centro Pompidou, del Museum of Modern Art (MoMA) (Hughston, 2012) o del Reina Sofía madrileño. Desde perspectivas más 
tradicionales, otros museos como el Prado o el Metropolitan, han empezado a considerar sus fondos bibliográficos antiguos como una más de sus colecciones, susceptibles por tanto de las prácticas museológicas habituales como exposiciones y catálogos.

\section{...y el lento camino a la visibilidad de los archivos}

Si el papel de las bibliotecas de museos ha sido irrelevante, al menos en nuestro país, todavía ha sido mayor la invisibilidad de los archivos. Concebidos ante todo al servicio de la gestión administrativa de la institución, sólo en los últimos tiempos se ha empezado a considerar su importancia para documentar las piezas del museo y estudiar la historia de la institución.

Su contenido, obviamente, ha sido y es la documentación generada por todos los departamentos del propio museo, desde la correspondencia de los directores a toda la información económica, de personal, sobre obras y exposiciones, etc. Además han venido recogiendo aquellos documentos o conjuntos documentales adquiridos o legados en virtud de su interés para el museo. El caso más abundante es el de los archivos personales. Porque son los archivos las unidades más adecuadas para custodiar estos conjuntos documentales al contar con los instrumentos de descripción y los lugares de almacenamiento apropiados. Por ello no tiene mucho sentido juntarlos con el resto de colecciones del museo en los Ilamados Fondos Documentales como establece de forma errónea la normativa ministerial española (Carretero, 1996).

Más interesante que las normas españolas son algunas pautas específicas, como las Museum archives guidelines, de la Society of American Archivists (2003), que establecen once directrices. Aunque algunas son genéricas, como las relativas a descripción, almacenamiento, acceso, etc., otras inciden en la especificidad del archivo de museo, como las referidas a definición y alcance, misión, estatus, etc.

La muestra más clara de la lenta conversión de los archivos de museos en recursos accesibles a todo el mundo es lógicamente su presencia en internet. Las primeras páginas específicas han comenzado suministrando información genérica sobre fondos y servicios y, en ocasiones, un cuadro de clasificación de todo o parte de la documentación. Buenos ejemplos son los archivos del Museo Picasso de París, o del MoMA de Nueva York (Hughston, 2012). El paso siguiente lo han dado aquellas instituciones que muestran el catálogo de su archivo en su web. Es el caso de dos museos londinenses, la Tate Gallery, que ofrece su archivo institucional y archivos de artistas y de instituciones artísticas británicas desde 1900 y de la National Gallery (figura 2).

Todos estos movimientos parecen augurar un futuro más prometedor a los archivos que a las bibliotecas de museos. El descubrimiento, difusión y digitalización de su desconocido patrimonio documental va a permitir reescribir algunos capítulos de la historia cultural insuficientemente estudiados. Por otro lado, el carácter único de su patrimonio puede ser un importante activo a la hora de competir en el mundo globalizado.

\section{El largo trayecto desde el libro-registro...}

El proceso documental dentro de los museos ha sido visto tradicionalmente como un mecanismo de control físico de las colecciones desde su entrada en la institución (registroinventario) hasta los movimientos posteriores. Por ello los servicios de documentación están ligados con frecuencia a los departamentos de registro, que son en realidad los auténticos responsables de este control. Este proceso necesitaba de una fase intermedia de catalogación científica que buscaba ante todo una identificación correcta de las piezas (GutiérrezUsillos, 2012). Los sistemas de gestión más al uso (Spectrum, Domus) desglosaban estos procedimientos en una prolija serie de pasos bien descritos en los manuales correspondientes (Carretero, 1996).

Los aspectos legales de propiedad y procedencia de las obras de museo, que en los últimos años han conocido numerosos episodios conflictivos, han estado también detrás del trabajo de los departamentos de documentación, preocupados por justificar la correcta adquisición y la legítima propiedad de sus colecciones (Marín-Torres, 2002).

Sólo en los últimos años ha comenzado a verse que los servicios documentales

Figura 2. Archivo de la National Gallery, Londres

http://www.nationalgallery.org.uk/archive 
de los museos debían avanzar en sus funciones en una triple dirección:

- coordinando elementos que hasta entonces habían funcionado por separado. Bibliotecas, archivos y departamentos de documentación tienen que contemplarse como las tres patas que sostienen la gestión de la información;

- proporcionando las herramientas básicas en las que deben confluir el trabajo de todos los departamentos, especialmente los que generan la mayor parte de las actividades de investigación: Conservación y Restauración;

- ser la raíz de toda la información que genera el museo cara al exterior, tanto la dirigida al gran público como la más especializada, bien en sus formas impresas o bien a través de los cauces que ofrecen las tecnologías de la información y la comunicación.

\section{...hasta la web semántica}

No es éste el lugar adecuado para trazar la historia, ya larga, de la presencia de los museos en internet. Recordaremos tan sólo algunos hitos. El primer museo del mundo en tener un sitio web fue el Exploratorium de San Francisco en el año 1993, al que siguieron museos de ciencias o museos didácticos de nuevo cuño antes que los grandes museos históricos. 1995 supuso la aparición masiva de sitios web de museos y dos años más tarde se celebró en Los Ángeles el primer congreso Museums and the Web, inicio de una serie que se ha convertido en el principal foro internacional sobre el tema. Mientras tanto los museos europeos y españoles comenzaban a integrarse en la Red, aunque lastrados por la tardanza en el desarrollo de la infraestructura de comunicaciones (banda ancha, ADSL) (Carreras-Monfort, 2003-2004). Estas primeras páginas web eran folletos electrónicos centrados en la presentación de datos de la propia institución: información general, historia, colecciones.

Cuando a partir de 2004 comenzó a extenderse la web 2.0 o web social, la actitud de los museos y de sus servicios documentales fue de nuevo bastante diferente a ambos lados del Atlántico. El carácter privado de la mayor parte de los museos estadounidenses hizo que se adaptasen mejor a unos instrumentos concebidos ante todo para la comunicación personal. Así, en los casi doscientos centros que aparecen en el grupo más importante de Facebook (Museums on Facebook, dentro de Musesphere), es abrumador el dominio anglosajón. Por otro lado, los museos europeos adoptaron con frecuencia en sus comunicaciones un carácter demasiado institucional contrario a la frescura interactiva que puede esperarse de las redes sociales. Dentro de esta corriente, los museos, e incluso sus bibliotecas, han ido abriendo también sus blogs (como la Ingalls Library del Cleveland Museum of Art), poniendo canales en Youtube o en Flickr (sin olvidar los podcasts) (Yasko, 2006), pero nunca parecen ser pione- ros en el uso de nuevos desarrollos sino más bien ir a remolque de los acontecimientos. Y no mencionaremos otros formatos como RSS, a los que los museos han llegado justo cuando parecen iniciar su agonía...

Tampoco es éste el lugar para recordar lo que está suponiendo el desarrollo de la web semántica, ni aquellos estándares en los que se soporta, pero es necesario echar una breve mirada al aprovechamiento que algunos museos están haciendo de sus posibilidades. Las primeras experiencias, como MuseumFinland en 2004 (Hyvönen et al., 2005) ya señalaron la mejora que el uso de ontologías o el empleo de esquemas de metadatos ofrecía para enriquecer las posibilidades de búsqueda y para extraer toda la información que pueden ofrecer las piezas de museo. Porque es importante señalar que estas obras no son sólo importantes para los profesionales de la disciplina tratada en el museo (historia del arte, arqueología, etnología, etc.) sino que muchas veces son también interesantes para estudiosos en otros campos que encuentran en los hechos y objetos representados una fuente novedosa para sus investigaciones. Como ejemplo pueden señalarse experiencias recientes llevadas a cabo por el Servicio de Documentación del Museo del Prado con ornitólogos o musicólogos.

Probablemente el caso más conocido y de mayor éxito ha sido el del British Museum que lanzó en 2011 una versión semántica de su extraordinario catálogo en línea. El nuevo servicio permite que los registros de su base de datos sean recolectados y reutilizados de acuerdo con la filosofía LOD (linked open data). Esta versión semántica aplica la ontología Cidoc-CRM (conceptual reference model), con la que se mejora las relaciones con otras organizaciones.

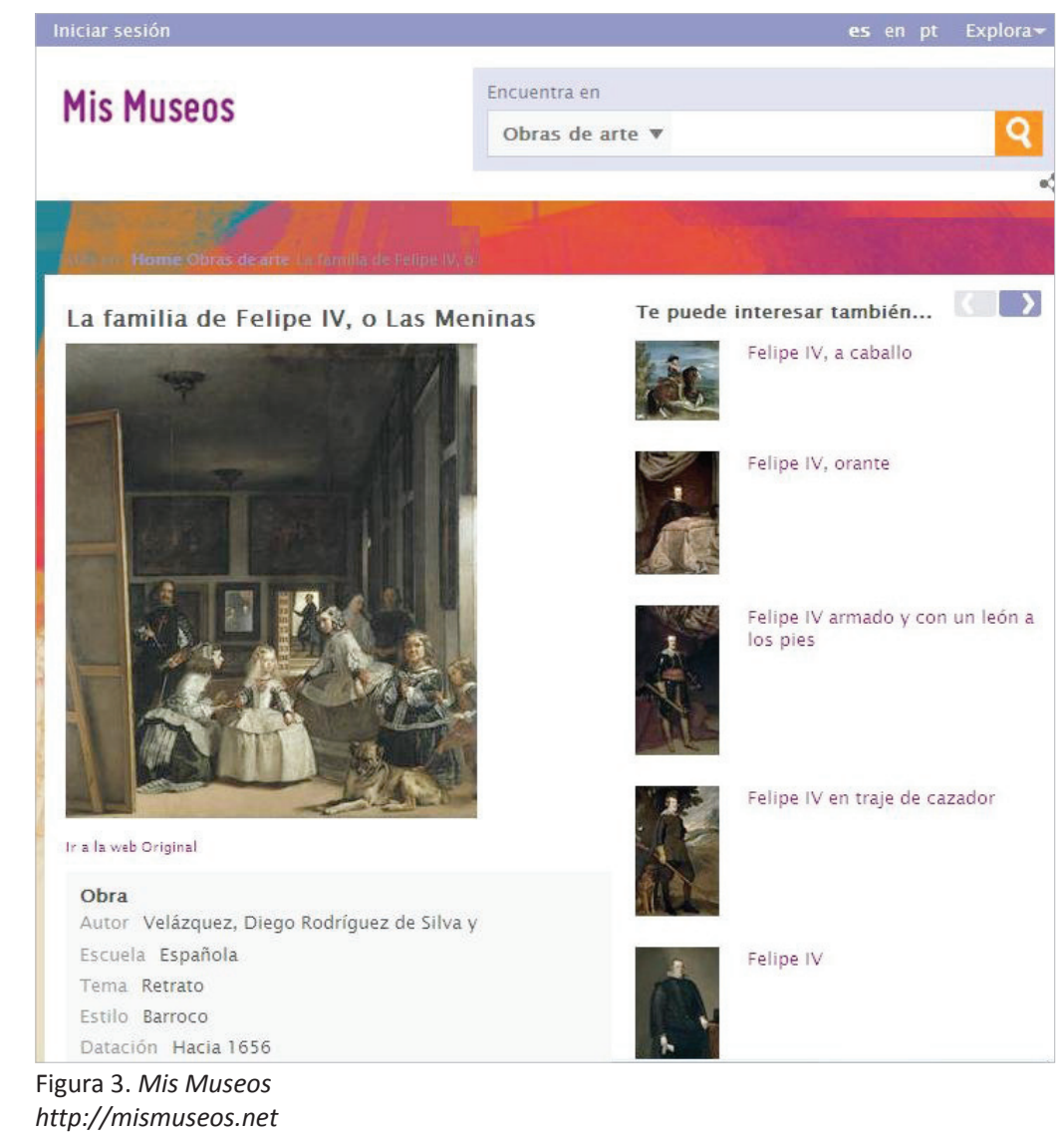


Más museos importantes, como la Smithsonian Institution o el Rijksmuseum de Amsterdam han comenzado a trabajar en esta línea. En nuestro país sólo conocemos una experiencia privada, Mis museos, que recoge unos 9.000 registros procedentes de Ceres.es y de las webs de otros museos, como el Prado. Aunque se trata de un sitio experimental, ofrece una ventana a lo que podría hacerse desde los museos españoles aprovechando las posibilidades de la web semántica (figura 3).

El Museo del Prado tiene intención de empezar a trabajar en esta línea y la próxima versión de su web partirá de la bases de datos de su colección de obras, además de las de biblioteca y archivo para implementar una web semántica y mejorar la accesibilidad, utilidad, transparencia e interacción de los fondos artísticos y documentales del Museo. Se facilitará el posible enlazado de sus datos con espacios LOD, de manera que puedan aparecer en otros contextos: de investigación, educativos, divulgativos, etc. La nueva web estará dotada de buscador facetado integrado, que permitirá que los resultados se muestren sumarizados en niveles y jerarquizados en función de propiedades y características definidas. También se pretende aplicar la citada ontología Cidoc-CRM, así como otros estándares habituales, como Dublin core y skos.

Sólo aquellas entidades capaces de ofrecer de forma generosa y gratuita la información devenida en conocimiento en torno a sus colecciones, podrán asegurarse un lugar en la nueva sociedad que está naciendo

\section{Una ruta aconsejable: la integración de servicios documentales...}

A pesar de que las bienintencionadas intenciones de las principales normativas internacionales llevan proponiéndolo desde hace mucho tiempo, lo cierto es que la integración de procesos y servicios en los sistemas documentales de museos es un hecho reciente. El objetivo final es simple: se trata de que el usuario reciba la información sobre cada una de las obras de la colección del museo de manera unificada, sea cual sea el tipo de información o la unidad que la ha generado.

En el caso concreto del Museo del Prado (Docampo; Martín-Bravo, 2009) se cuenta con un programa de documentación y gestión de la colección que recoge la información generada por los diferentes servicios del museo (Registro, Exposiciones, Restauración, Gabinete Técnico) mientras que el servicio de documentación se encarga de completarla mediante la recopilación de los datos de catalogación de las obras, así como el establecimiento de los vínculos con las bases de datos de archivo y biblioteca

Es posible que la variedad de información que se maneja dentro de los museos, alguna de ella confidencial por cuestiones de seguridad de las obras o por afectar a datos personales de trabajadores del museo, obligue a establecer distintos niveles de acceso, pero esto no debe impedir dar la máxima transparencia a la información sobre las colecciones, con las únicas limitaciones derivadas de la legislación vigente.

\section{...pero una única meta: la Web}

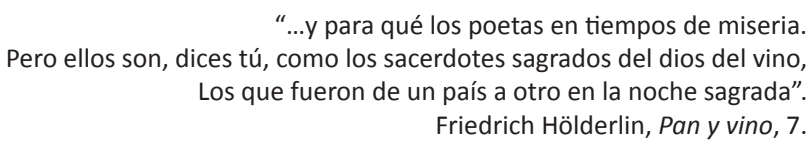

“...y para qué los poetas en tiempos de miseria. Pero ellos son, dices tú, como los sacerdotes sagrados del dios del vino, Los que fueron de un país a otro en la noche sagrada". Friedrich Hölderlin, Pan y vino, 7.

Los museos son instituciones complejas. Representan, al menos en el Viejo Mundo y muchas veces a su pesar, las esencias de la patria y el recuerdo de sus glorias pasadas. Museos como el Louvre, el Prado o el Británico son los herederos de las cámaras del tesoro medievales y como ellas la encarnación de lo más valioso que atesora una comunidad.

Por ello son a veces instituciones resistentes al cambio, lugares en los que se teme perder la identidad si se proyecta hacia el exterior todo el conocimiento acumulado en ellos durante muchos años. Sin embargo en estos tiempos de miseria sólo la difusión de este conocimiento puede hacer de los museos entidades sostenibles y con futuro. Porque como nos han contado recientemente, acudiendo al inspirador símil de las ceremonias potlatch de los indios norteamericanos (Ortega; Rodríguez-López, 2011), sólo aquellas entidades capaces de posicionarse públicamente a través del ofrecimiento generoso y gratuito de uno de sus principales activos, la información devenida en conocimiento en torno a sus colecciones, podrán asegurarse un lugar en la nueva sociedad que está naciendo. Y en este proceso el papel fundamental sólo puede ser ejercido por los servicios documentales del museo.

\section{Bibliografía}

Alonso-Sáez, Raúl (2012). "La Red de Bibliotecas de Museos (BIMUS)". En: Primeras Jornadas sobre Bibliotecas de Museos: nuevos medios y nuevos públicos. Madrid: Ministerio de Educación, Cultura y Deporte, pp. 153-165.

http://www.mcu.es/museos/docs/Primeras_Jornadas_ BIMUS.pdf

Benedetti, Joan M. (ed.) (2007). Art museum libraries and librarianship. Lanham: Scarecrow Press; Ottawa: Art Libraries Society of North America, 2007.

Carreras-Monfort, César (2003-2004). “Museografía en Internet: análisis de la situación en nuestro país" en Boletín do Museo Provincial de Lugo, n. 11, 2, pp. 95-116.

http://dialnet.unirioja.es/servlet/articulo?codigo $=1281570$

Carretero-Pérez, Andrés et al. (1996). Normalización documental de museos: elementos para una aplicación informática de gestión museográfica. Madrid: Ministerio de Educacion y Cultura, 1996.

http://www.mcu.es/museos/MC/NDM/index.html

Docampo-Capilla, F. Javier (2010). "Bibliotecas de museos: panorama internacional de una tipología bibliotecaria". Educación y biblioteca, v. 22, n. 176, p. 60-71.

http://gredos.usal.es/jspui/bitstream/10366/119711/1/ EB22_N176_P60-71.pdf 
Docampo-Capilla, F. Javier; Martín-Bravo, Ana (2009). “EI Área de Biblioteca, Archivo y Documentación del Museo Nacional del Prado: hacia una integración de procesos y servicios". XI Jornadas de gestión de la información: Servicios polivalentes, confluencia entre profesionales de archivo, biblioteca y documentación. Madrid, 19-20 nov., pp. 53-66. http://hdl.handle.net/10760/13878

Gómez-Martínez, Javier (2006). Dos museologías: las tradiciones anglosajona y mediterrónea: diferencias y contactos. Gijón: Trea, 2006.

Gutiérrez-Usillos, Andrés (2012). Manual práctico de museos. Gijón: Trea.

Hoyer, Rüdiger (2012). "Artlibraries.net, WorldCat and common initiatives for the future of art bibliography". Art Libraries Section open session, IFLA World library and information congress, Helsinki.

http://goo.gl/zRAZj

Hughston, Milan R. (2012). "Learning machines, wunderkammers, and networks in documenting the art of our time = Máquinas de aprendizaje, cuartos de maravillas y redes en la documentación del arte de nuestro tiempo". $1^{\text {as }}$ jornadas sobre bibliotecas de museos: nuevos medios y nue- vos públicos. Madrid, Mำ de Educación, Cultura y Deporte, pp. 93-113.

http://www.mcu.es/museos/docs/Primeras_Jornadas_ BIMUS.pdf

Hyvönen, Eero; Mäkelä, Eetu; Salminen, Mirva; Valo, Arttu; Viljanen, Kim; Saarela, Samppa; Junnila, Miikka; Kettula, Suvi (2005). "MuseumFinland. Finnish museums on the semantic web". Web semantics: science, services and agents on the world wide web, v. 3, n. 2-3, Oct., pp. 224-241. http://dx.doi.org/10.1016/j.websem.2005.05.008

Marín-Torres, María-Teresa (2002). Historia de la documentacion museológica. La gestion de la memoria artística. Gijón: Ediciones Trea.

Museum archives guidelines (2003). Society of American Archivists. http://www2.archivists.org/standards/museum-archivesguidelines

Ortega, José-Felipe; Rodríguez-López, Joaquín (2011). El potlatch digital: Wikipedia y el triunfo del procomún y el conocimiento compartido. Madrid: Cátedra, 2011.

Yasko, James (2006). "Podcasting in museums". Journal of museum studies: The journal of the Masters in museum studies program, The University of Oklahoma, v. 1, n. 1, pp. 1-35.

\section{Próximos temas centrales}

Julio 2013

Septiembre 2013

Noviembre 2013

Enero 2014

Marzo 2014

Mayo 2014

Julio 2014

Septiembre 2014

Noviembre 2014
Economía de la información

Gestión de contenidos

Formación y aprendizaje

Documentación audiovisual

Políticas de información

Humanidades digitales

Big data y analítica web

Marketing

Web semántica

Los interesados por favor consulten detenidamente las Normas para autores: http://www.elprofesionaldelainformacion.com/autores.html

y luego envíen sus artículos a través del gestor de manuscritos OJS de la plataforma del Recyt: http://recyt.fecyt.es/index.php/EPI/index 